\title{
Output Problem
}

National Cancer Institute

\section{Source}

National Cancer Institute. Output Problem. NCI Thesaurus. Code C62941.

Problem associated with any deviation from the documented specifications of the device that relate to the end result, data, or test results provided by the device. 